\title{
Influence of surrounding wall thickness on the fatigue resistance of molars restored with ceramic inlay
}

\section{Shizuma SHIBATA(a) Renata GONDO (a) Élito ARAÚJO (a) Carlos Rodrigo de Mello ROESLER ${ }^{(b)}$ Luiz Narciso BARATIERI(a)}

(a)Department of Dental Sciences, Centre of Heath Sciences, Univ. Federal de Santa Catarina - UFSC, Florianópolis, SC, Brazil.

(b) Deparment of Mechanical Engineering, Biomechanics Engineering Laboratory, University Hospital, Univ. Federal de Santa Catarina - UFSC, Florianópolis, SC, Brazil.

Declaration of Interests: The authors certify that they have no commercial or associative interest that represents a conflict of interest in connection with the manuscript.

Corresponding author:

Shizuma Shibata

E-mail:shizumas@hotmail.com

DOI: 10.1590/1807-3107BOR-2014.vol28.0011 Epub Jun 02, 2014

Submitted: Sep 05, 2013

Accepted for publication: Jan 28, 2014

Last revision: Feb 19, 2014

\begin{abstract}
The purpose of this study was to evaluate the influence of buccal and lingual wall thickness on the fatigue resistance of molars restored with CAD/CAM ceramic inlays. Forty human third molars were selected and divided into 4 groups, according to the remaining surrounding wall thickness chosen for inlay preparation $(n=10)$ : G1, $2.0 \mathrm{~mm}$; G2, $1.5 \mathrm{~mm}$; G3, $1.0 \mathrm{~mm}$; G4, $0.5 \mathrm{~mm}$. All inlays were made from feldspathic ceramic blocks by a CAD/CAM system, and cemented adhesively. After 1 week stored in distilled water at $37^{\circ} \mathrm{C}$, the specimens were subjected to fatigue testing under the following protocol: $5 \mathrm{~Hz}$; pre-load of $200 \mathrm{~N}$ for 5,000 cycles, followed by increasing loads of $400,600,800,1000,1200$ and $1400 \mathrm{~N}$ for 30,000 cycles each. The specimens were cycled until failure or completion of 185,000 cycles. The survival rate of the groups was compared using the Kaplan-Meier survival curves $(p>0.05)$. All specimens withstood the fatigue protocol $(185,000$ cycles), representing a $100 \%$ survival rate. The Kaplan-Meier survival curves showed no difference between groups. It can be concluded that the remaining tooth wall thickness did not influence the fatigue resistance of molars restored with CAD/CAM ceramic inlays.
\end{abstract}

Keyword: Stress, Mechanical; Ceramics; Inlays.

\section{Introduction}

Inlay restorations are indirect intracoronary restorations, with no involvement of cusps, and involving a more conservative procedure than crowns. ${ }^{1}$ While a full crown preparation removes about $67.5 \%$ to $75.6 \%$ of dental tissue, a typical inlay preparation removes about $20 \% .^{2}$ Moreover, inlay restorations have a high clinical success rate in long-term longitudinal studies, namely, a $96 \%$ survival rate in 4 years, up to $85.7 \%$ in 10 years. ${ }^{3,4}$ However, a recurrent question regarding inlay restorations relates to cavity design, especially regarding the occlusal isthmus extension, and to when the cusps should be overlapped. $5,6,7,8,9$ In the literature, recommendations can be found indicating that when the limits of the inlay cavity preparations are closer than $1.5 \mathrm{~mm}$ to the functional cusp, or when there is a less than $2 \mathrm{~mm}$ remaining thickness, an onlay preparation should be included, with a $2 \mathrm{~mm}$ axial reduction. ${ }^{10}$

This principle of cavity preparation with cuspal coverage or overlap is based on metal cast restorations that do not adhere to dental substrates, and that are recommended to strengthen a weakened tooth 
structure. ${ }^{5}$ However, the advent of adhesive dentistry, in conjunction with improvements in the mechanical properties of restorative materials and their manufacturing process, has enabled restorations to recover all or part of weakened tooth resistance, thus increasing the possibility of more conservative restorative procedures. ${ }^{5,6,7}$

With the prospects of less invasive preparations and greater preservation of tooth structure, it became necessary to reassess how much of the remaining tooth should be maintained for preparing an indirect inlay restoration, without compromising tooth integrity. Therefore, the aim of the study was to evaluate the influence of 4 different thicknesses $(2.0 \mathrm{~mm}$, $1.5 \mathrm{~mm}, 1.0 \mathrm{~mm}$ and $0.5 \mathrm{~mm}$ ), at the base of the surrounding walls (buccal and lingual), on the fatigue resistance of molar teeth restored with CAD/CAM ceramic inlays. The null hypothesis tested was that the remaining wall thicknesses of cavity preparations would not influence the fatigue resistance of teeth restored with ceramic inlays.

\section{Methodology}

This study was approved by the Human Research Ethics Committee of the Universidade Federal de Santa Catarina (UFSC), Process no. 2054/FR no. 425608. Forty sound human third molars, without caries or visible cracks, and of similar size (<5\% deviation), were selected. The teeth were cleaned and remained stored in distilled water at $37^{\circ} \mathrm{C}$ throughout the study. All teeth were embedded in acrylic resin (Clássico, São Paulo, Brazil) $3 \mathrm{~mm}$ below the cementoenamel junction, in a $25 \mathrm{~mm}$ diameter PVC cylinder (Tigre, Joinville, Brazil). A device was developed to standardize the preparation step. When attached to a dental surveyor (Bioart, São Carlos, Brazil), it enabled the high speed handpiece (Kavo, Joinville, Brazil) to be maintained in a stable position, and the long axis of the diamond burs (KG Sorensen, Cotia, Brazil) to be kept parallel to the shaft of the dental surveyor (Bioart, São Carlos, Brazil) and perpendicular to the occlusal surface. The dental preparations were performed with no. 3131 diamond burs (KG Sorensen, Cotia, Brazil), followed by no. 3131F (KG Sorensen, Cotia, Brazil) and no. 3131FF diamond burs (KG Sorensen, Cotia, Brazil).
New diamond burs were used after every 5 preparations. The dental surveyor, the high speed handpiece and the diamond burs were kept in the same position throughout the preparation procedures. The specimens were then moved manually, by the same operator, to perform the dental preparation.

As a last consideration, the characteristics of the cavity design were as follows: MOD preparation, without a proximal box for better standardization; divergent internal walls with a $10^{\circ}$ to $15^{\circ}$ tilt; rounded internal angles; cavosurface angle with no bevel, $4 \mathrm{~mm}$ cavity depth from the cusp tips; and buccal and lingual surrounding wall thickness according to each group evaluated. The tooth wall thicknesses were determined using a digital caliper (Model 727; Starrett, Itu, Brazil), measuring the base of each surrounding wall and diving the walls into 4 groups, accordingly (Figure 1A - 1D): G1, $2.0 \mathrm{~mm}( \pm 0.1 \mathrm{~mm}) ; \mathrm{G} 2,1.5 \mathrm{~mm}( \pm 0.1 \mathrm{~mm}) ; \mathrm{G} 3,1.0$ $\mathrm{mm}( \pm 0.1 \mathrm{~mm}) ; \mathrm{G} 4,0.5 \mathrm{~mm}( \pm 0.1 \mathrm{~mm})$.

The impression, design and milling of the ceramic inlays were performed using an in-office CAD/CAM system (Cerec 3D Software V. 3.03; Sirona Dental $\mathrm{GmbH}$, Salzburg, Austria). The design of all the ceramic restorations was determined using the Biogeneric app of the CAD/CAM system. All the restorations were made from feldspathic ceramic blocks (Vitablocs Mark II; Vita Zahnfabrik, Bad Säckingen, Germany). After the milling process, the inlays were polished (OptraFine; Ivoclar Vivadent AG, Schaan, Liechtenstein) and their adaptation was checked. All ceramic restorations were cemented adhesively in the dual curing mode. The description of the adhesive systems, the cementing agent, and the silane and light-curing unit used in this study is provided in Table 1. After 24 hours stored in distilled water at $37^{\circ} \mathrm{C}$, the inlay margins were polished (OptraFine; Ivoclar Vivadent AG, Schaan, Liechtenstein), and the inlays were subsequently stored in distilled water at $37^{\circ} \mathrm{C}$ for 7 days before submitting them to the fatigue test.

The fatigue test was performed in a dynamic servo-hydraulic machine (model BME 200 160/AT; Brasválvulas, São Paulo, Brazil), according to a load cell model TU-K2C (Gefran, Provaglio D'Iseo, Italy) and $2000 \mathrm{~N}$ maximal load capacity, certified by Certi Foundation, Protocol number 3972/11 

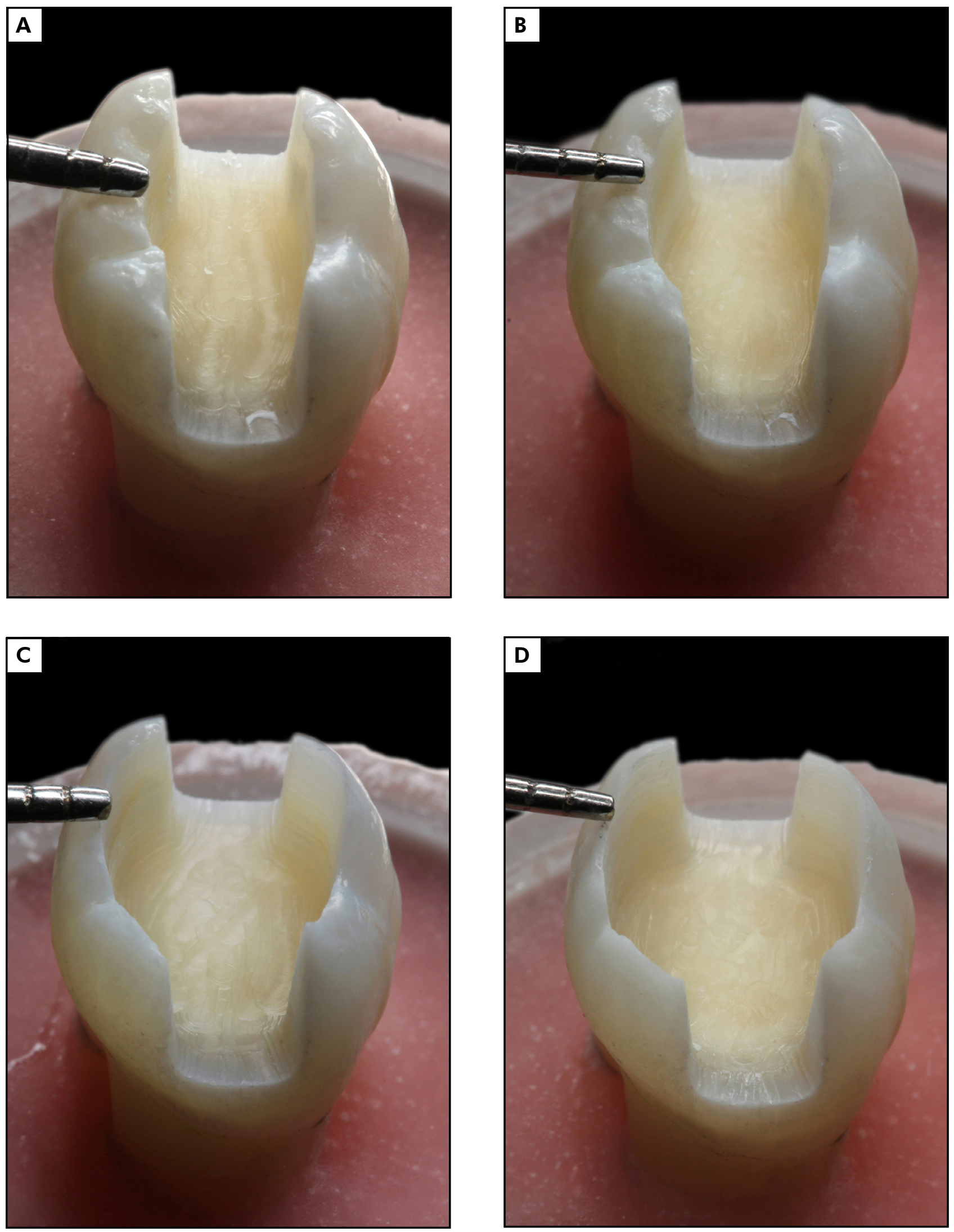

Figure 1. (A) G1: $2.0 \mathrm{~mm}$. (B) G2: $1.5 \mathrm{~mm}$. (C) G3: $1.0 \mathrm{~mm}$. (D) G4: $0.5 \mathrm{~mm}$. 
Table 1. Adhesive system, resin cement and silane used, together with ingredients and application procedures, according to the manufacturers.

\begin{tabular}{|c|c|c|c|}
\hline Material & Composition & Application procedures & Manufacturer \\
\hline $\begin{array}{l}\text { Adper Scotchbond } \\
\text { Multipurpose Plus Activator }\end{array}$ & $\begin{array}{l}\text { Ethyl alcohol, sodium } \\
\text { benzenesulfinate }\end{array}$ & $\begin{array}{l}\text { 1. Mix one drop each of activator and primer. } \\
\text { 2. Apply to etched enamel and dentin - wait } \\
\qquad 15 \text { seconds. }\end{array}$ & 3M ESPE, St. Paul, USA \\
\hline $\begin{array}{l}\text { Adper Scotchbond } \\
\text { Multipurpose Plus Primer }\end{array}$ & $\begin{array}{c}\text { Water, HEMA, copolymer of acrylic } \\
\text { and itaconic acids }\end{array}$ & 3. Dry gently for 5 seconds. & 3M ESPE, St. Paul, USA \\
\hline $\begin{array}{l}\text { Adper Scotchbond } \\
\text { Multipurpose Plus Catalyst }\end{array}$ & $\begin{array}{l}\text { BISGMA, HEMA, benzoyl peroxide, } \\
\text { triphenylphosphine }\end{array}$ & $\begin{array}{l}\text { 1. Apply to the primed enamel, dentin and } \\
\text { core material. } \\
\begin{array}{c}\text { 2. Apply to the treated bonding surface of the } \\
\text { indirect restoration. }\end{array}\end{array}$ & 3M ESPE, St. Paul, USA \\
\hline $\begin{array}{l}\text { RelyX ARC Adhesive } \\
\text { Resin Cement }\end{array}$ & $\begin{array}{l}\text { Silane treated ceramic, TEGDMA, } \\
\text { BISGMA, silane treated silica, } \\
\text { functionalized dimethacrylate } \\
\text { polymer, 2-benzotriazolyl-4- } \\
\text { methylphenol, } 4 \text {-(dimethylamino)- } \\
\text { benzeneethanol }\end{array}$ & $\begin{array}{l}\text { 1. Dispense the cement onto a mixing pad. } \\
\text { 2. Mix for } 10 \text { seconds. } \\
\text { 3. Apply to the bonding surface of the } \\
\text { indirect restoration. } \\
\text { 4. Slowly seat and hold restoration. } \\
\text { 5. Light-cure each cement surface/margin for } \\
40 \text { seconds. }\end{array}$ & 3M ESPE, St. Paul, USA \\
\hline MonoBond S & $\begin{array}{c}\text { Ethanol, Water, Acetic Acid, } \\
\text { 3-ethacryloxypropyl-trimethoxysilane }\end{array}$ & $\begin{array}{c}\text { Apply to the pre-treated surfaces. Allow the } \\
\text { material to react for } 60 \text { seconds. Disperse with } \\
\text { a strong stream of air. }\end{array}$ & $\begin{array}{l}\text { Ivoclar Vivadent AG, } \\
\text { Schaan, Liechtenstein }\end{array}$ \\
\hline Tranlux Power Blue & $\begin{array}{l}\text { LED light-curing unit, } \\
440-480 \mathrm{~nm} \text { wavelength range, } \\
1,000 \mathrm{~mW} / \mathrm{cm} \text { light intensity }\end{array}$ & $\begin{array}{l}\text { Performed according to the adhesive system } \\
\text { and resin cement manufacturer's instructions. }\end{array}$ & $\begin{array}{l}\text { Heraeus Kulzer, } \\
\text { Hanau, Germany }\end{array}$ \\
\hline
\end{tabular}

(Certi Foundation, Florianopolis, Brazil). The test was performed by placing the specimen on a metal platform attached to the dynamic testing machine. This platform consisted of a metal base, a resistor (with temperature control) and an acrylic chamber fixed to the base, which was filled with distilled water for testing. The water temperature was maintained at $37^{\circ} \mathrm{C}$ to simulate oral temperature. ${ }^{11}$ After fixing the specimen in the platform firmly, a vertical load was placed directly on the occlusal surface, using a 6-mm-diameter metal sphere (Figure 2). Initially, a preload of $200 \mathrm{~N}$ for 5000 cycles was applied, using sinusoidal cyclic loading at $5 \mathrm{~Hz}$. Physiologically, tooth contact during the masticatory cycle occurs in 0.25 to 0.33 seconds or 1.57 to $1.58 \mathrm{~Hz}$, on average, taking into account the whole cycle. ${ }^{11,12}$ Nevertheless, in order to accelerate the test, a cycle of $5 \mathrm{~Hz}$ was used..$^{13}$ After the pre-load stage, all specimens were subjected to increasing loads of 400,600, 800, 1000, 1200 and $1400 \mathrm{~N}$ for a maximum of 30,000 cycles each. The test was performed by completing the maximum cycles $(185,000)$, or else fracture of the specimen.
The fracture mode was classified according to the following criteria: Mode I, small fractures in tooth structure or ceramic; Mode II, fracture of one or more cusps, with fracture above the cementoenamel junction; Mode III, longitudinal fracture compromising the integrity of the tooth or beyond the cementoenamel junction. Mode I and II were considered non-catastrophic failures, and restorable, whereas Mode III was considered catastrophic and non-restorable.

\section{Statistical analysis}

The fatigue resistance of each group was compared statistically by the Kaplan-Meier survival curve, which considers the number of specimens that start the test in each group compared to those fractured throughout the test, and which forms a survival probability. The influence of the remaining prepared tooth wall thickness was analyzed by comparing the survival curves using a log-rank test at a 5\% significance level. Statistical analysis was performed with SPSS Statistics 19 (IBM, New York, USA). 


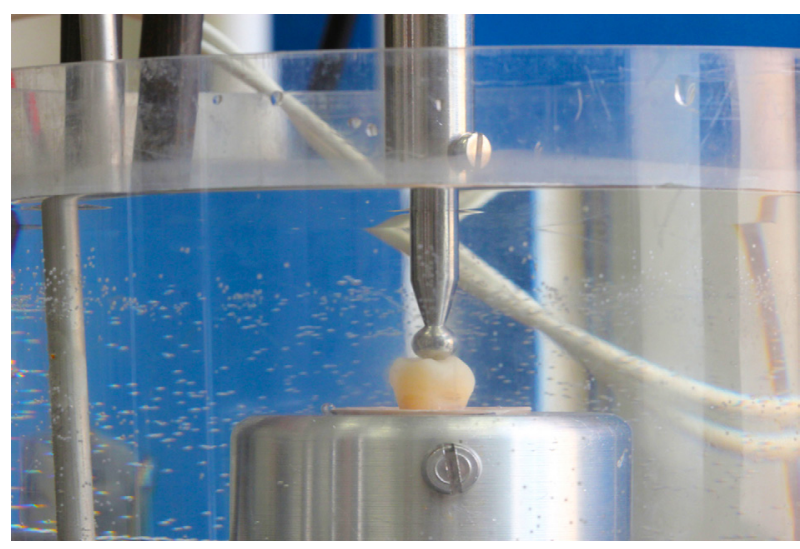

Figure 2. Specimen attached to the platform and submerged in distilled water, with the metal ball positioned in the center of the tooth for fatigue testing.

\section{Results}

Because all specimens withstood the fatigue protocol, there was no specimen fracture after 185,000 cycles, yielding a $100 \%$ survival rate, with no visible signs of failure in the ceramic or the tooth (Table 2). The Kaplan-Meier survival curves showed no difference between the groups, considering that all specimens survived the fatigue protocol. It was assumed that all of the specimens were censored, i.e., they reached the end of study without failing. Therefore, there were no data for post hoc log-rank testing to investigate the influence of the remaining wall thickness on the survival rate (Figure 3 ).

Table 2. Test groups, number of specimens, number of failures and specimen survival rate.

\begin{tabular}{|c|c|c|c|c|}
\hline \multirow{2}{*}{ Groups } & \multirow{2}{*}{$\begin{array}{l}\text { Number of } \\
\text { Specimens }\end{array}$} & \multirow{2}{*}{ Failures } & \multicolumn{2}{|c|}{ Survival Rate } \\
\hline & & & $n$ & Percent \\
\hline $\mathrm{Gl}-2.0 \mathrm{~mm}$ & 10 & 0 & 10 & $100.0 \%$ \\
\hline $\mathrm{G} 2-1.5 \mathrm{~mm}$ & 10 & 0 & 10 & $100.0 \%$ \\
\hline $\mathrm{G} 3-1.0 \mathrm{~mm}$ & 10 & 0 & 10 & $100.0 \%$ \\
\hline $\mathrm{G} 4-0.5 \mathrm{~mm}$ & 10 & 0 & 10 & $100.0 \%$ \\
\hline Total & 40 & 0 & 40 & $100.0 \%$ \\
\hline
\end{tabular}

\section{Discussion}

In the present study, no difference was found in the fatigue resistance of molars restored with CAD/ CAM ceramic inlays with $2.0 \mathrm{~mm}, 1.5 \mathrm{~mm}, 1.0 \mathrm{~mm}$ or $0.5 \mathrm{~mm}$ surrounding wall thicknesses. Therefore, the null hypothesis that surrounding wall thickness does not affect the fatigue resistance of a tooth-restoration complex was accepted. The current findings are in accordance with the suggestions by Stappert $e t$ $a l .,^{5}$ who propose that more studies be performed in relation to inlay cavity design limits. This suggestion was made after the aforementioned authors assessed the fracture resistance of inlays, onlays and natural teeth, and found no statistical differences in the mean fracture resistance of the tested groups, even after they were submitted to 1.2 million loading cycles.

In the present study, the ceramic inlay thickness and volume varied between groups due to the cavity design - a variable that could influence tooth strength in each group. However, the finite element analysis showed that the fracture risk of ceramic inlays was not associated as much with ceramic thickness as with ceramic type; e.g., more rigid ceramics, such as lithium disilicate, have a lower principal stress, ranging between 20.7 to 22.1 $\mathrm{MPa}$. Conversely, leucite ceramic (a less rigid ceramic) had a greater principal stress, i.e., 27.6 to $29.2 \mathrm{MPa}$, even when different thicknesses were tested. ${ }^{14}$

Compared to the aforementioned ceramics, the feldspar ceramics used in this study had lower values of flexural resistance. ${ }^{15}$ However, the controlled sintering process could account for the high resistance to propagation of the ceramic cracks. In this process, leucite crystals are heated until they become polymorphic sanidine crystals of feldspar, which have a higher contraction rate upon cooling than the original crystals. ${ }^{15,16}$ These characteristics may have led, in part, to the behavior of the restorations observed in this study. Moreover, in ceramic restorations, higher stress concentrations occur on the ceramic restoration surface, as is the case of natural teeth. This characteristic protects the adhesive interface from compression or mastication stresses. Moreover, ceramic inlays can recover tooth structure rigidity better than resin composite restorations. ${ }^{17}$

Restorations in the oral cavity are predominantly subject to cyclic loading in a wet environment. This is the main cause for the development and growth of cracks, which reduce the strength of restorative materials, or lead to their failure. ${ }^{18,19}$ The development of a crack can be facilitated by pre-existing faults in 


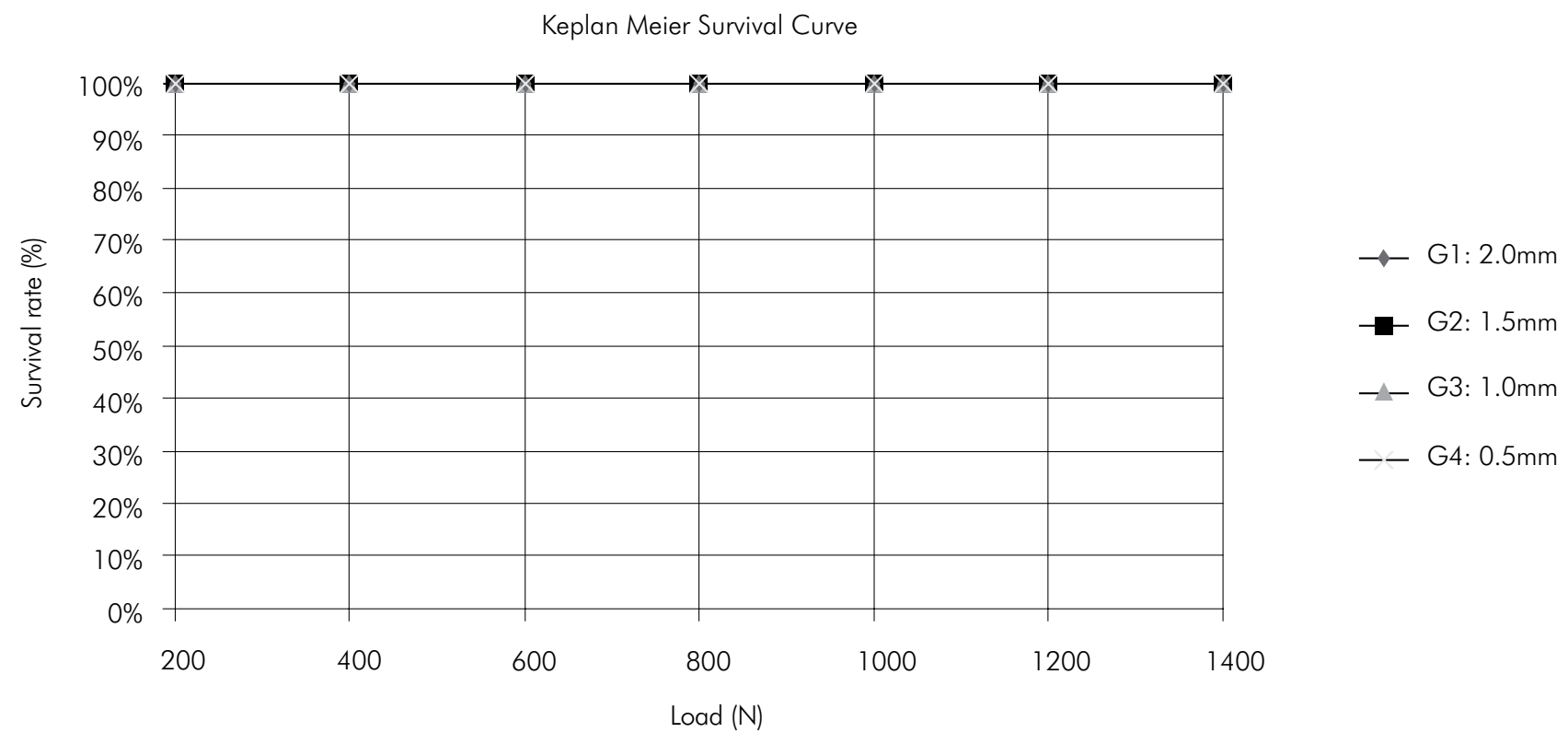

Figure 3. Kaplan-Meier survival curves for 4 different surrounding wall thicknesses $(2.0 \mathrm{~mm}, 1.5 \mathrm{~mm}, 1.0 \mathrm{~mm}$ and $0.5 \mathrm{~mm})$. All specimens survived the fatigue protocol.

the restoration, occurring during the manufacturing process, or pre-existing cracks in the tooth. ${ }^{20,21}$ Taking this into account, in-office CAD/CAM technology can fashion an indirect restoration in a single session or moment, ${ }^{22}$ avoiding new cracks during the temporization period, ${ }^{20}$ and can provide restorations made from industrially manufactured ceramic or from composite blocks, which have minor internal flaws, as compared with traditional laboratory restorations. ${ }^{21}$

Results obtained from randomized controlled clinical trials are the best option for comparing or evaluating biomaterials or restorative techniques; however, they present many variables, high costs and ethical issues. ${ }^{11,23}$ For these reasons, laboratory studies that simulate conditions or situations that may be found clinically, such as fatigue tests using a servohydraulic machine, may be a suitable option for the first and initial evaluation. ${ }^{11}$ In normal conditions, the chewing cycle varies from 0.2 to $1.5 \mathrm{~Hz}$, and a masticatory load in molar regions is approximately $360 \mathrm{~N}$; in addition, 1.2 million cycles correspond to 5 years of clinical function. ${ }^{5,8}$ One drawback of following the standard guidelines for making laboratory assessments is the time required to complete the test. Therefore, this study chose to follow a protocol presented by Magne and Knezevic, ${ }^{13}$ adapted from an original study by Fennis et al. ${ }^{24}$ This methodology is presented as a balance between the classic fatigue tests with low loads for millions of cycles and the compression tests, ${ }^{25}$ insofar as the specimens were subjected to loads that were within physiological limits and that were of extrinsic origin, such as those occurring as a result of trauma. ${ }^{25}$

Although all of the specimens survived the proposed test, the results of this research should be analyzed within its limitations. Krifka et al. ${ }^{9}$ demonstrated that preparations with reduced cusps resulted in better marginal integrity and reduced crack formation than teeth without cusp reduction. Thus, it could be assumed that a higher number of cycles may result in statistically significant failures; however, the time required for carrying out the cyclic tests until complete fracture is a limitation in fatigue tests. It is a common occurrence to have no failures even after 1.2 million cyclic loads with low load intensity. ${ }^{8}$ The fatigue protocol performed in this study was chosen precisely for this reason; other studies using the same protocol found fractures in specimens. ${ }^{13,25}$

Nevertheless, there are other limitations to the present study design. It is possible that the load applied may not have been challenging enough to fracture the tested specimens. In a study performed 
by Saridag et al., ${ }^{26}$ the mean fracture strength found in molar teeth restored by a lithium-disilicate ceramic inlay was $2646.7( \pm 360.4) \mathrm{N}$. Thus, further studies are warranted to determine the influence of more challenging situations than those applied in the present study, including the use of higher loads, of test groups with non-restored teeth or inlays cemented with non-adhesive cements, and of test groups with the same wall thickness, but with cusp reduction.

\section{Conclusion}

Within the limitations of this study, it may be concluded that remaining tooth wall thickness did not

\section{References}

1. Jackson RD. Indirect resin inlay and onlay restorations: a comprehensive clinical overview. Pract Periodontics Aesthet Dent. 1999 Oct;11(8):891-900; quiz 902.

2. Edelhoff D, Sorensen JA. Tooth structure removal associated with various preparation designs for posterior teeth. Int J Periodontics Restorative Dent. 2002 Jun;22(3):241-9.

3. Krämer N, Ebert J, Petschelt A, Frankenberger R. Ceramic inlays bonded with two adhesives after 4 years. Dent Mater. 2006 Jan;22(1):13-21.

4. Zimmer S, Göhlich O, Rüttermann S, Lang H, Raab WHM, Barthel CR. Long-term survival of Cerec restorations: a 10year study. Oper Dent. 2008 Oct;33(5):484-7.

5. Stappert CFJ, Abe P, Kurths V, Gerds T, Strub JR. Masticatory fatigue, fracture resistance, and marginal discrepancy of ceramic partial crowns with and without coverage of compromised cusps. J Adhes Dent. 2008 Feb;10(1):41-8.

6. Fonseca RB, Fernandes-Neto AJ, Correr-Sobrinho L, Soares CJ. The influence of cavity preparation design on fracture strength and mode of fracture of laboratoryprocessed composite resin restorations. J Prosthet Dent. 2007 Oct;98(4):277-84.

7. Morimoto S, Vieira GF, Agra CM, Sesma N, Gil C. Fracture strength of teeth restored with ceramic inlays and overlays. Braz Dent J. 2009;20(2):143-8.

8. Stappert CFJ, Att W, Gerds T, Strub JR. Fracture resistance of different partial-coverage ceramic molar restorations: an in vitro investigation. J Am Dent Assoc. 2006 Apr;137(4):514-22.

9. Krifka S, Stangl M, Wiesbauer S, Hiller K-A, Schmalz G, Federlin M. Influence of different cusp coverage methods for the extension of ceramic inlays on marginal integrity and enamel crack formation in vitro. Clin Oral Investig. 2009 Sep;13(3):333-41. influence the fatigue resistance of molars restored with CAD/CAM ceramic inlays.

\section{Acknowledgements}

We would like to thank Dr. Med. Ari Digiacomo Ocampo Moré and technician Daniel João Lúcio for their significant contributions to the undertaking and analysis of this study. The authors also wish to acknowledge Laboratório de Engenharia Biomecânica do Hospital Universitário (LEBm - UFSC) for providing the lab facility. The present study was supported in part by the Conselho Nacional de Desenvolvimento Cientifico (CNPq), grant no. 134164/2011-3.

10. Banks RG. Conservative posterior ceramic restorations: a literature review. J Prosthet Dent. 1990 Jun;63(6):619-26.

11. DeLong R, Douglas WH. An artificial oral environment for testing dental materials. IEEE Trans Biomed Eng. 1991 Apr;38(4):339-45.

12. Po JMC, Kieser JA, Gallo LM, Tésenyi AJ, Herbison P, Farella M. Time-frequency analysis of chewing activity in the natural environment. J Dent Res. 2011 Oct;90(10):1206-10.

13. Magne $P$, Knezevic A. Simulated fatigue resistance of composite resin versus porcelain CAD/CAM overlay restorations on endodontically treated molars. Quintessence Int. 2009 Feb;40(2):125-33.

14. 14. Holberg C, Rudzki-Janson I, Wichelhaus A, Winterhalder P. Ceramic inlays: Is the inlay thickness an important factor influencing the fracture risk? J Dent. 2013 Jul;41(7):628-35.

15. Deany IL. Recent advances in ceramics for dentistry. Crit Rev Oral Biol Med. 1996;7(2):134-43.

16. Boushell LW, Ritter AV. Ceramic inlays: a case presentation and lessons learned from the literature. J Esthet Restor Dent. 2009;21(2):77-87.

17. Magne P, Belser UC. Porcelain versus composite inlays/ onlays: effects of mechanical loads on stress distribution, adhesion, and crown flexure. Int J Periodontics Restorative Dent. 2003 Dec;23(6):543-55.

18. Kelly JR. Clinically relevant approach to failure testing of allceramic restorations. J Prosthet Dent. 1999 Jun;81(6):652-61.

19. Ohyama T, Yoshinari M, Oda Y. Effects of cyclic loading on the strength of all-ceramic materials. Int J Prosthodont. 1999 Feb;12(1):28-37.

20. Frankenberger R, Krämer N, Appelt A, Lohbauer U, Naumann M, Roggendorf MJ. Chairside vs. labside ceramic inlays: Effect of temporary restoration and adhesive luting on enamel cracks and marginal integrity. Dent Mater. 2011 Sep;27(9):892-8. 
21. Giordano R. Materials for chairside CAD/CAM-produced restorations. J Am Dent Assoc. 2006 Sep;137 Suppl:14S-21S.

22. Mörmann WH. The evolution of the CEREC system. J Am Dent Assoc. 2006 Sep;137 Suppl:7S-13S.

23. Anusavice KJ, Kakar K, Ferree N. Which mechanical and physical testing methods are relevant for predicting the clinical performance of ceramic-based dental prostheses?. Clin Oral Implants Res. 2007 Jun;18 Suppl 3:218-31.

24. Fennis WMM, Kuijs RH, Kreulen CM, Verdonschot N, Creugers NHJ. Fatigue resistance of teeth restored with cuspal-coverage composite restorations. Int J Prosthodont. 2004 Jun;17(3):313-7.

25. Schlichting LH, Maia HP, Baratieri LN, Magne P. Noveldesign ultra-thin CAD/CAM composite resin and ceramic occlusal veneers for the treatment of severe dental erosion. J Prosthet Dent. 2011 Apr;105(4):217-26.

26. Saridag S, Sevimay M, Pekkan G. Fracture resistance of teeth restored with all-ceramic inlays and onlays: an in vitro study. Oper Dent. 2013 Dec;38(6):626-34. 